\title{
Population structure and historical demography of eastern North Atlantic harbour porpoises inferred through mtDNA sequences
}

\author{
K. A. Tolley ${ }^{1,2, *}$, P. E. Rosel ${ }^{3}$ \\ ${ }^{1}$ Marine Mammal Division, Institute of Marine Research, PO Box 1870, Nordnes, 5024 Bergen, Norway \\ ${ }^{2}$ Molecular Systematics Laboratory, South African National Biodiversity Institute, Private Bag X7, Claremont 7735, \\ Cape Town, South Africa \\ ${ }^{3}$ National Marine Fisheries Service, 646 Cajundome Blvd., Suite 234, Lafayette, Louisiana 70506, USA
}

\begin{abstract}
The harbour porpoise Phocoena phocoena experiences high rates of incidental mortality in commercial fisheries, and in some areas these rates are sufficiently high to justify concern over population sustainability. Given this high mortality, conservation efforts may be facilitated by an understanding of how present-day population structure has been shaped by historical demographic changes. To investigate the demographic history of porpoises in the eastern North Atlantic, variation in the mitochondrial DNA (mtDNA) control region of 115 porpoises was compared among 4 sampling locations (North Sea, France, Portugal, and West Africa). Genetic variation was investigated by analysis of molecular variance (AMOVA) and spatial analysis of molecular variance (SAMOVA). To put the present study in context within the eastern Atlantic, previously published sequence data from Norway $(n=87)$ and the Black Sea $(n=9)$ were included. All areas showed substantial geographic structure as indicated by AMOVA and SAMOVA, and there was significant isolation by distance among sampling areas. The haplotype network, mismatch distribution and Fu's $F_{S}$ test of population equilibrium suggest there has been a relatively recent range expansion into the northernmost area (Norway), probably as a result of re-colonisation into regions previously iced over during Quaternary glaciation events. In all, these results suggest that harbour porpoises within the eastern North Atlantic show geographic structuring as a consequence of limited gene flow along the coast, and their historical biogeography can be interpreted in light of demographic changes that have influenced the evolutionary patterns observed in the mtDNA sequences.
\end{abstract}

KEY WORDS: Demographic history $\cdot$ Phocoenidae $\cdot$ Palaeoclimate $\cdot$ Leading edge effect $\cdot$ Population structure

Resale or republication not permitted without written consent of the publisher

\section{INTRODUCTION}

The harbour porpoise Phocoena phocoena is a small cetacean restricted to coastal and continental shelf waters of the North Atlantic, North Pacific, and the Black Sea. In the North Atlantic, the species inhabits coastal waters of northern Africa, Europe, and North America (see Fig. 1). They are absent from the Mediterranean, and thorough investigation has led to the conclusion that they have been historically absent from the region (Frantzis et al. 2001). Some recent observa- tions have been made on the Mediterranean side of the Straits of Bosporus (Frantzis et al. 2001), but these appear to be Black Sea individuals that have entered the region (Rosel et al. 2003). Although the distribution of harbour porpoises in the North Atlantic is essentially continuous, there are deep oceanic waters between landmasses, which could potentially interrupt this seemingly continuous distribution (see Donovan \& Bjørge 1995). Hence, there is potential for population fragmentation around isolated landmasses (e.g. Iceland, Greenland, Faeroe Islands) as demonstrated by 
Tolley et al. (2001), and/or isolation by distance in the areas of apparent continuous habitat and distribution (e.g. from West Africa to the Barents Sea, or along the coast of North America).

The genetic population structure of harbour porpoises in some regions of the North Atlantic has been studied previously using both nuclear and mitochondrial markers (e.g. Rosel et al. 1999, Andersen et al. 2001, Tolley et al. 2001). In some areas, population structure is striking, and suggests that harbour porpoises are philopatric (e.g. Wang et al. 1996, Wang \& Berggren 1997, Rosel et al. 1999). Ecological markers such as organochlorine loads (Westgate \& Tolley 1999), radioactive caesium levels (Tolley \& Heldal 2002), and satellite tagging (Read \& Westgate 1997, K. Tolley, unpubl. data) also suggest that porpoises are relatively philopatric within a region. Despite this, in some areas of the North Atlantic, genetic differences are either low or have not been detected (Walton 1997, Tolley et al. 1999, Andersen et al. 2001, Tolley et al. 2001). Hence, the question arises as to what forces have shaped the demographic history of porpoises in the North Atlantic with the result that genetic population structure is low although it might be expected to be pronounced.

Population history is reflected in the currently observable genetic structure (Hewitt 2000). In the case of recently fragmented populations, or recently colonized areas, common ancestral haplotypes will be retained in high frequency, even if there is little or no contemporary gene flow. Environmental changes that cause range distributions to shift, expand or contract will play a role in shaping population history. Such range constriction and expansion cycles have been inferred for a number of terrestrial mammals based on genetic data, as the distributions of these organisms have changed in response to large-scale environmental changes (see review in Hewitt 2000). For harbour porpoises, oceanic temperature changes and sea ice cover should be expected to play a role in causing distributional changes. Porpoises are presently distributed in Atlantic coastal waters with a thermal zone that ranges from the polar front $\left(\mathrm{ca} .0 .5^{\circ} \mathrm{C}\right.$ ), southwards to a 20 to $24^{\circ} \mathrm{C}$ thermocline (Fig. 1). Their restriction to this zone may be due to thermal requirements or to some other factor such as seasonal prey abundance, and we hypothesise that their distribution would presumably follow any shifts or changes in the size of this zone at any past, present or future time. Hence, it may be possible to make inferences regarding their demographic history, given what is known of paleoclimatic changes in the North Atlantic.

The genetic population structure of harbour porpoises in the North Atlantic has been dealt with extensively in the literature, with the exception of the south- eastern North Atlantic (from the English Channel southwards to West Africa). Previous mitochondrial DNA (mtDNA) studies suggest that there is a fair degree of population structure in the western North Atlantic, and that the northern reaches of the eastern and western Atlantic were probably recolonised from different sources after the last glaciation (Rosel et al. 1995, Wang et al. 1996, Tolley et al. 2001). In the eastern North Atlantic, population structure determined by mtDNA is not as pronounced as in the western North Atlantic, with many areas sampled showing little or weak genetic differentiation (Walton 1997, Wang \& Berggren 1997, Tolley et al. 1999). The objective of this study was to investigate patterns of contemporary genetic population structure focussing on a region not previously investigated, i.e. the southeastern North Atlantic, and to examine those patterns in light of what is known about paleoclimatic changes in the region. In addition, previously published sequences of porpoises from nearby regions (the Black Sea and Norway) were included in this study. This allowed for a comparison of patterns among regions that may have been influenced differently by climatic shifts.

\section{MATERIALS AND METHODS}

Tissue samples were obtained opportunistically from harbour porpoises either beachcast, or by-caught in commercial fishing nets from the southeastern North Sea $(\mathrm{n}=47)$, France $(\mathrm{n}=49)$, Portugal $(\mathrm{n}=14)$, and West Africa $(\mathrm{n}=5)$ (Fig. 1). In addition, 9 individuals from the eastern Black Sea sequenced by Rosel et al. (1995), and 87 individuals from the coast of Norway sequenced by Tolley et al. (1999, our Fig. 1) were included in the analysis. Soft tissues (muscle, skin, or kidney) were preserved in either $70 \%$ ethanol, or $20 \%$ dimethylsulfoxide saturated with sodium chloride, or consisted of dried skin obtained from museum specimens. For some individuals, only hard tissues (teeth and bones) were available.

Total genomic DNA was extracted from soft tissues following a standard proteinase-K digestion followed by phenol/chloroform as in Tolley et al. (2001). For hard tissues, all surfaces were cleaned with 10\% bleach and irradiated with UV light to ensure that there was no surface contamination prior to DNA extraction. Teeth were crushed to powder using a Biopulverizer (Biospec Products). For bones, ca. $40 \mathrm{mg}$ of powder was obtained by drilling holes into the bone fragments with a sterilized drill bit (2 to $3 \mathrm{~mm}$ diameter). The powdered tooth or bone tissue was digested in $1 \mathrm{ml}$ of extraction buffer $\left(0.2 \mathrm{mg} \mathrm{ml}^{-1}\right.$ proteinase $\mathrm{K}$, $0.5 \mathrm{M}$ EDTA pH 8.3, $1 \% \mathrm{~N}$-lauryl-sarcosine) for 3 to $4 \mathrm{~d}$ at room temperature on a rotating mixer in the dark. 


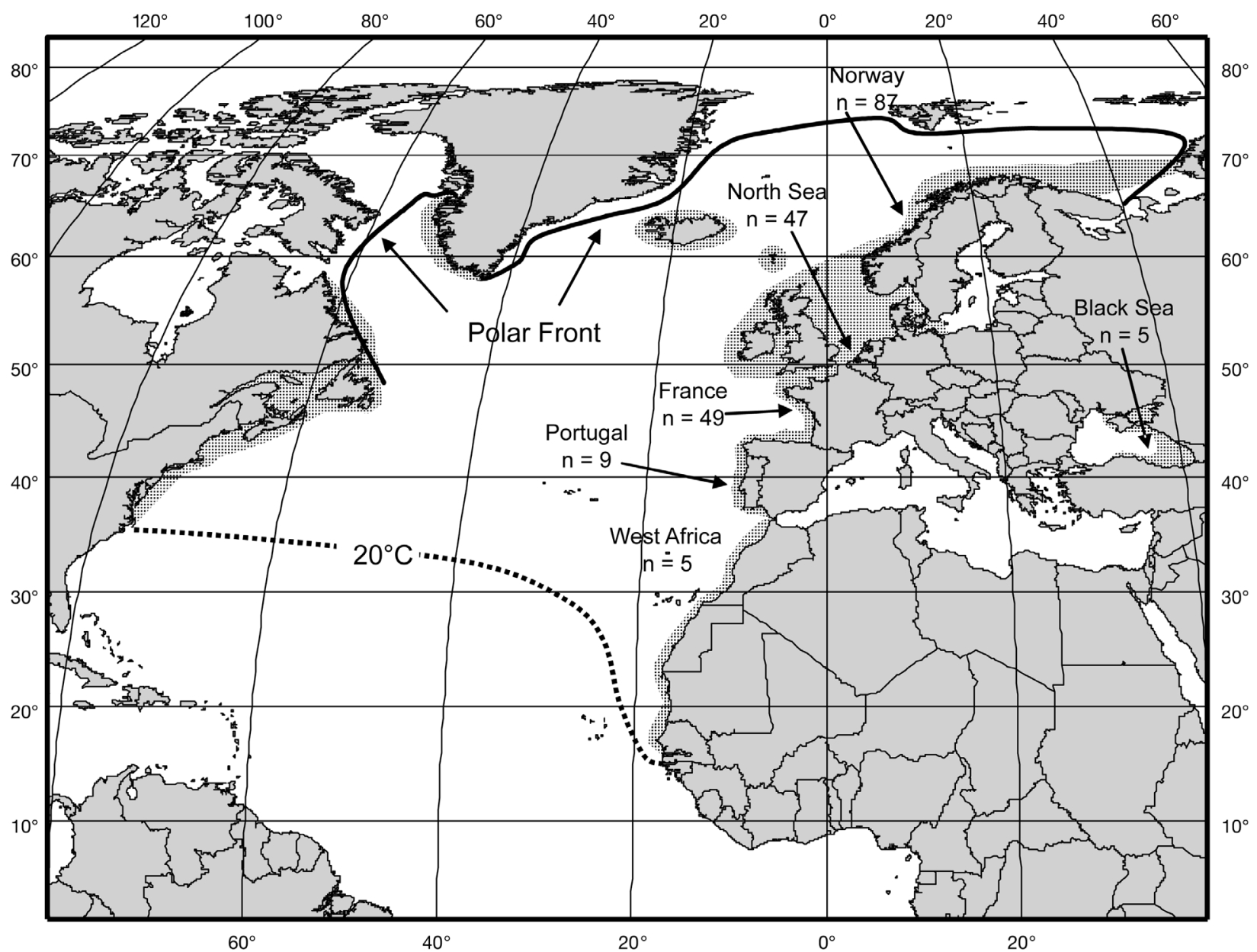

Fig. 1 Phocoena phocoena. Primary distribution in the North Atlantic shown in dark grey. Sampling areas and samples sizes for Norway, the North Sea (Netherlands and Belgium), France, Portugal, West Africa, and the Black Sea are given. Samples were collected from across the coastline of each region, except for West Africa (Mauritania only) and the Black Sea (eastern Black Sea only). Solid line: present location of the polar front; dotted line: present day $20^{\circ} \mathrm{C}$ thermocline

An additional $5 \mu \mathrm{l}$ proteinase $\mathrm{K}\left(20 \mathrm{mg} \mathrm{ml}^{-1}\right)$ was added each day. After digestion, the extract was spun down and the supernatant removed. One half volume phe$\mathrm{nol} /$ chloroform $(1: 1 \mathrm{v} / \mathrm{v})$ was added to the supernatant, which was mixed, spun down, and the aqueous layer removed. The aqueous phase was then transferred to a Centricon YM-30 filter to further clean and then recover the DNA extract, following the manufacturer's protocol (Millipore).

A 441 base pair (bp) fragment from the hypervariable region I of the mtDNA control region and a portion of the flanking proline tRNA was amplified using the polymerase chain reaction (PCR) with primers L15824 and H16265 (Rosel et al. 1999). Amplification was carried out with $50 \mathrm{ng}$ genomic DNA in a reaction containing $50 \mathrm{mM}$ $\mathrm{KCl}, 10 \mathrm{mM}$ Tris- $\mathrm{HCl} \mathrm{pH} \mathrm{9.0,} 1.5$ to $5 \mathrm{mM} \mathrm{MgCl}_{2}, 0.3 \mu \mathrm{M}$ of each primer, $0.2 \mathrm{mM}$ dNTPs and 1.0 to 2.5 units of Taq DNA polymerase. For some reactions, 0.08 to $0.64 \mu \mathrm{g} \mathrm{\mu l} \mathrm{l}^{-1}$ bovine serum albumen was included to enhance amplification. In the case of hard tissues and dried skin, only low molecular weight DNA was obtained, and it was necessary to amplify and then concatenate sequences of 2 smaller fragments. Two overlapping primer sets were used: A new primer, L15867 (5'-ACC AAC ACC CAA AGC TGG-3'), was paired with H16075 (5'-GGC TTT AAC ATA GTC GT-3') (Rosel et al. 1995) to amplify the upstream portion of the target region. The downstream segment of the target region was amplified with a second new primer, L16061 (5'-GCT ATG TAT TAT TGT GCA TTC-3') paired with H16265. Amplified PCR products were purified on $1 \%$ or $2.5 \%$ (depending on fragment size) low melting point gel, and the bands were excised and digested with $1.5 \mu \mathrm{l}$ of $5 \mathrm{U} \mathrm{\mu l}^{-1}$ agarase in a water bath for $2 \mathrm{~h}$ at $40^{\circ} \mathrm{C}$. The cleaned product was cycle sequenced using fluorescent labelled dye-terminators (ABI) following the manufacturer's protocols, ethanol precipitated, and analysed on an ABI Prism 310 Genetic Analyzer. All fragments were sequenced in both the forward and reverse directions. Sequences were edited using Sequence Navigator (ABI) and consensus 
sequences from the forward and reverse directions were aligned using ClustalX (Thompson et al. 1997) with the default alignment parameters.

Haplotype diversity $(h)$ and nucleotide diversity $(\pi)$ were estimated in Arlequin 2.0 (Schneider et al. 2000). An analysis of molecular variance (AMOVA) was conducted to estimate the degree of differentiation among the 6 sampling areas using 2 measures of genetic differentiation $\left(F_{\mathrm{ST}}\right.$ and $\left.\Phi_{\mathrm{ST}}\right)$ in Arlequin 2.0.

$\Phi_{\mathrm{ST}}$ was estimated using the Tamura-Nei model of evolution, as determined by Modeltest 3.6 (Posada \& Crandall 1998). In addition, to provide a context for the southeastern Atlantic in a larger perspective that covers the entire North Atlantic, an a posteriori AMOVA was carried out on sequences available from previous studies (Rosel et al. 1999, Tolley et al. 2001). This larger data set included porpoises from 5 additional individual sampling areas: Iceland, west Greenland, Newfoundland, Gulf of St. Lawrence and the Gulf of Maine. Full details regarding these sampling areas, locality details, and GenBank Accession numbers can be found in the original studies (Rosel et al. 1999, Tolley et al. 2001).

To further investigate population structure, a spatial analysis of molecular variance (SAMOVA) was used to identify possible genetic barriers in the sampling region (Dupanloup et al. 2002). A Mantel test was used to investigate isolation by distance using genetic distance $\left(D_{A}\right)$ and geographic distance between the centre points of sampling areas $(\log \mathrm{km})$. The significance value of the relationship was estimated by 10000 random permutations using Mantel for Windows Ver. 1.11 (http:// life.bio.sunysb.edu/morph/).

Fu's $F_{S}$ test (Fu 1997) is a particularly useful test for estimating whether a population is out of mutation-drift equilibrium, and such populations may have experienced recent demographic changes (Fu 1997, Excoffier \& Schneider 1999, Schneider et al. 2000). Significance values were estimated using 10000 permutations. To further investigate this possibility, Arlequin 2.0 (Schneider et al. 2000) was used to construct a mismatch distribution, which was tested against a model of demographic expansion (Excoffier \& Schneider 1999). A rough esti- mate for the age $(T)$ of demographic changes in the North Atlantic was obtained by: $T=\tau /(2 \times u)$, where $T$ is time in generations, $\tau$ is the age of the expansion in mutational units (estimated in the model of demographic expansion), and $u$ is the mutation rate in the region sequenced (Rogers 1995). To obtain $T$, a mutation rate for the specific region of DNA investigated is needed. There is ca. $6 \%$ mtDNA sequence divergence between por-

Table 1. Phocoena phocoena. Haplotype frequencies for the sampling areas of harbour porpoises in the eastern North Atlantic and Black Sea. Haplotypes shared between the southeast North Atlantic (present study) and Norway (Tolley et al. 2001) are indicated by an asterisk, and haplotype names from both studies are given where they differed. S: new haplotype series

\begin{tabular}{|c|c|c|c|c|c|c|c|}
\hline & lack Sea & W. Africa & Portugal & France & North Sea & Norway & Total \\
\hline N1 ${ }^{*}$ & - & - & - & 13 & 39 & 40 & 92 \\
\hline S1 & - & - & - & 1 & 1 & - & 2 \\
\hline $\mathrm{S} 2$ & - & - & - & 4 & 4 & - & 8 \\
\hline S3 & - & - & - & - & 1 & - & 1 \\
\hline $\mathrm{S} 4$ & - & - & - & 1 & 1 & - & 2 \\
\hline S5 & - & - & - & - & 1 & - & 1 \\
\hline S6 & - & - & 8 & 14 & - & - & 22 \\
\hline S7 & - & - & - & 3 & - & - & 3 \\
\hline S8 & - & - & 4 & 6 & - & - & 10 \\
\hline S9 & - & - & - & 1 & - & - & 1 \\
\hline $\mathrm{S} 10$ & - & - & - & 2 & - & - & 2 \\
\hline S11 & - & - & - & 2 & - & - & 2 \\
\hline S12/N12 & $2^{*}-$ & - & - & 1 & - & 4 & 5 \\
\hline $\mathrm{S} 13$ & - & - & 1 & 1 & - & - & 2 \\
\hline S14/N18 & $3^{*}-$ & - & 1 & - & - & 1 & 2 \\
\hline S15 & - & 2 & - & - & - & - & 2 \\
\hline S16 & - & 2 & - & - & - & - & 2 \\
\hline S17 & - & 1 & - & - & - & - & 1 \\
\hline BS1 & 8 & - & - & - & - & - & 8 \\
\hline BS2 & 1 & - & - & - & - & - & 1 \\
\hline N2 & - & - & - & - & - & 1 & 1 \\
\hline N3 & - & - & - & - & - & 7 & 7 \\
\hline N4 & - & - & - & - & - & 6 & 6 \\
\hline N5 & - & - & - & - & - & 1 & 1 \\
\hline N6 & - & - & - & - & - & 1 & 1 \\
\hline N7 & - & - & - & - & - & 1 & 1 \\
\hline N8 & - & - & - & - & - & 2 & 2 \\
\hline N9 & - & - & - & - & - & 2 & 2 \\
\hline N10 & - & - & - & - & - & 1 & 1 \\
\hline N11 & - & - & - & - & - & 1 & 1 \\
\hline N13 & - & - & - & - & - & 1 & 1 \\
\hline N14 & - & - & - & - & - & 2 & 2 \\
\hline N15 & - & - & - & - & - & 1 & 1 \\
\hline N16 & - & - & - & - & - & 1 & 1 \\
\hline N17 & - & - & - & - & - & 2 & 2 \\
\hline N19 & - & - & - & - & - & 1 & 1 \\
\hline N20 & - & - & - & - & - & 2 & 2 \\
\hline N21 & - & - & - & - & - & 1 & 1 \\
\hline N22 & - & - & - & - & - & 1 & 1 \\
\hline N23 & - & - & - & - & - & 1 & 1 \\
\hline N24 & - & - & - & - & - & 1 & 1 \\
\hline N25 & - & - & - & - & - & 1 & 1 \\
\hline N26 & - & - & - & - & - & 1 & 1 \\
\hline N27 & - & - & - & - & - & 1 & 1 \\
\hline N29 & - & - & - & - & - & 1 & 1 \\
\hline IC14 & - & - & - & - & - & 1 & 1 \\
\hline Total & 9 & 5 & 14 & 49 & 47 & 87 & 211 \\
\hline
\end{tabular}


poises from the Atlantic and Pacific Oceans, as estimated from all sequences available on GenBank (calculation not shown), and the 2 ocean basins were last in contact across the Arctic approximately 700000 to $900000 \mathrm{yr}$ ago, with seasonal ice and estimated sea surface temperatures of ca. $0.5^{\circ} \mathrm{C}$ (Harris 2005). Within the last ca. $700000 \mathrm{yr}$, there appear to have been episodic events of seasonal ice, but estimated sea surface temperatures were less than ca. $0.5^{\circ} \mathrm{C}$ (Harris 2005), a sea temperature at which porpoises are not typically found today. Using the most recent estimate of suitable conditions (sea temperatures higher than $0.5^{\circ} \mathrm{C}$, with no perennial ice; 700000 to $900000 \mathrm{yr}$ ) as a rough calibration point, a substitution rate for the porpoise control region was estimated at ca. $\mu=3.3$ to $4.3 \%$ per site per million yr (Myr). The data did not violate the assumption of a constant molecular clock as estimated in PAUP 4.0b10 (Swofford 2002; Likelihood Ratio Test, LRT $=34.96, \mathrm{df}=44 ; \mathrm{ns}$ ), so this range of rates for a constant clock was applied in dating demographic events. The generation time used for the calculation of $u$ was $7 \mathrm{yr}$ (A. J. Read pers. comm.), with a final estimate of $u=(356 \mathrm{bp} \times 7 \mathrm{yr} \times \mu)$. Thus, we estimate $u$ ranged from 0.0000822 to 0.0001072 , which represents the substitution rate per generation across $356 \mathrm{bp}$ of the control region used here.

Finally, to investigate geographic patterns in the relationships among haplotypes and their frequencies in each sampling area, a median joining network of haplotypes was constructed in Network 4.0 (www.fluxusengineering.com/).

\section{RESULTS}

A consensus region of 356 base pairs of the mitochondrial control region (hypervariable region I) was obtained. A total of 18 haplotypes were identified among the 115 harbour porpoises from the southeastern North Atlantic, of which 15 were new and 3 were shared with the previously sequenced Norwegian samples (Table 1, GenBank Accession nos. AY262369 to AY262386). An additional 2 haplotypes were present in the Black Sea (Rosel et al. 1995) and were unique to that region (Table 1, BS1 and BS2; GenBank Accession nos. AY262387 and AY262388 (cross reference to U09690- U09691). Although Rosel et al. (1995) found 3 haplotypes in the Black Sea, the sequences were truncated to $356 \mathrm{bp}$ for this study, causing 2 of the original haplotypes to become merged. In total, there were 21 polymorphic sites (18 transitions, 1 transversion, 3 indels). Haplotype diversity (h) ranged from 0.222 to 0.834 , and
Table 2. Phocoena phocoena. Haplotype $(h)$ and nucleotide diversity $(\pi)$, with $95 \%$ confidence intervals, for 6 sampling areas in the eastern North Atlantic and the Black Sea. Sample size (n) and number of haplotypes per population (No.) are also given. Sequence data for the Black Sea and Norway are taken from Rosel et al. (1995) and Tolley et al. (2001)

\begin{tabular}{|lcccc|}
\hline & n & No. & $h$ & $\pi$ \\
\hline Black Sea & 9 & 2 & $0.222( \pm 0.166)$ & $0.0006( \pm 0.0009)$ \\
W. Africa & 5 & 3 & $0.800( \pm 0.164)$ & $0.0090( \pm 0.0065)$ \\
Portugal & 14 & 4 & $0.626( \pm 0.110)$ & $0.0038( \pm 0.0028)$ \\
France & 49 & 12 & $0.834( \pm 0.032)$ & $0.0087( \pm 0.0051)$ \\
North Sea & 47 & 6 & $0.309( \pm 0.085)$ & $0.0029( \pm 0.0022)$ \\
Norway & 87 & 29 & $0.779( \pm 0.046)$ & $0.0090( \pm 0.0052)$ \\
\hline
\end{tabular}

nucleotide diversity $(\pi)$ from 0.0006 to 0.0090 (Table 2 ). The most common haplotype was $\mathrm{N} 1$, accounting for $42 \%$ of all individuals sequenced and occurring most frequently in Norway. This haplotype was not present in Portugal, the Black Sea, or West Africa; however, these populations had the smallest sample sizes and may not represent the complete distribution of haplotypes present in those areas. Neither West Africa nor the Black Sea shared haplotypes with any of the other regions.

The AMOVA showed significant differences for both $F_{\mathrm{ST}}$ and $\Phi_{\mathrm{ST}}$ among all sampling localities (Table 3). Overall values for $F_{\mathrm{ST}}(0.22, \mathrm{p}<0.001)$ and $\Phi_{\mathrm{ST}}(0.40$, $\mathrm{p}<0.001$ ) were the highest observed yet in this species within an ocean basin. The a posteriori AMOVA showed that all southeastern North Atlantic sampling areas were significantly different $\left(\Phi_{\mathrm{ST}}\right.$ ranging between 0.09 and $0.40, \mathrm{p}<0.001$ ) from the sampling areas in the previous studies (Iceland, West Greenland, Gulf of St. Lawrence, Gulf of Maine). This corroborates the conclusion by Rosel et al. (1999b) that there is limited gene flow between the eastern and western North Atlantic.

The SAMOVA results show that the maximal genetic divergence among populations (where $F_{\mathrm{CT}}$ is highest) occurs when only 2 hierarchical groups are defined: the Black Sea and the eastern Atlantic $\left(\right.$ Table $4 ; F_{\mathrm{CT}}=$

Table 3. Phocoena phocoena. Pairwise comparisons from the AMOVA for harbour porpoises from the eastern North Atlantic and the Black Sea. Conventional $F_{\mathrm{ST}}$ statistics are given above the diagonal, and $\Phi_{\mathrm{ST}}$ below the diagonal. Significance values (p) were generated by 10000 random permutations. ${ }^{*} \mathrm{p}<0.05,{ }^{* *} \mathrm{p}<0.01,{ }^{* * *} \mathrm{p}<0.001$, ns: not significant

\begin{tabular}{|lcccccc|}
\hline & Black Sea & W. Africa & Portugal & France & North Sea & Norway \\
\hline Black Sea & - & $0.555^{* * *}$ & $0.546^{* * *}$ & $0.373^{* * *}$ & $0.711^{* * *}$ & $0.7392^{* * *}$ \\
W. Africa & $0.834^{* * *}$ & - & $0.309^{* *}$ & $0.178^{* *}$ & $0.585^{* * *}$ & $0.214^{* * *}$ \\
Portugal & $0.866^{* * *}$ & $0.462^{* * *}$ & - & $0.076^{* *}$ & $0.588^{* * *}$ & $0.278^{* * *}$ \\
France & $0.666^{* * *}$ & $0.311^{* *}$ & $0.162^{* *}$ & - & $0.258^{* * *}$ & $0.081^{* * *}$ \\
North Sea & $0.892^{* * *}$ & $0.747^{* * *}$ & $0.755^{* * *}$ & $0.357^{* * *}$ & - & $0.105^{\mathrm{ns}}$ \\
Norway & $0.666^{* * *}$ & $0.459^{* * *}$ & $0.474^{* * *}$ & $0.182^{* * *}$ & $0.076^{* * *}$ & - \\
\hline
\end{tabular}


0.55). With respect to the eastern Atlantic sampling areas, the genetic divergence among regions is maximised when only 2 Atlantic populations are defined: (1) West Africa and (2) all others along the European coast combined (Table $4 ; F_{\mathrm{CT}}=0.50$ ). Significant differences were also detected among the European sampling areas using AMOVA, but the SAMOVA suggests that the European sampling areas can be grouped together and are distinct from the West Africa samples, possibly suggesting a genetic barrier between the 2 continents. In addition, the Atlantic as a whole forms a hierarchical group (Europe and West Africa) that is distinct from the Black Sea, suggesting a second, perhaps stronger genetic barrier between the Atlantic and the Black Sea.

There was significant correlation between genetic and geographic distance between sampling areas (Mantel test; $r=0.82$, $p<0.01$; Fig. 2) which can be interpreted as the occurrence of isolation by distance within the sampling area. Isolation by distance was also tested only among the Eastern Atlantic sampling areas (excluding the Black Sea). This relationship was also found to be significant $(r=0.67, p<0.05)$ suggesting the presence of isolation by distance along the Atlantic seaboard. However, if only the European sampling areas are included, the relationship is not significant $(\mathrm{r}=0.59)$.

Given the results of the SAMOVA, Fu's $F_{S}$ was run on the 3 groups (Black Sea, West Africa, European coast), as well as for each sampling area. $F_{S}$ was not significant for the Black Sea $\left(F_{S}=-0.3\right)$ or West Africa

Table 4. Phocoena phocoena. Results of the SAMOVA for the eastern North Atlantic and the Black Sea sampling locations. $F$ statistics for this hierarchical spatial model are given for each level of possible groupings. Significance values (p) were generated by 10000 random permutations. ${ }^{*} \mathrm{p}<0.05,{ }^{* *} \mathrm{p}<0.01,{ }^{* * *} \mathrm{p}<0.001$, ns: not significant, N/A: not applicable

\begin{tabular}{|lccc|}
\hline Groups & $F_{\mathrm{SC}}$ & $F_{\mathrm{ST}}$ & $F_{\mathrm{CT}}$ \\
\hline $\begin{array}{l}\text { 1. Black Sea } \\
\text { 2. All others }\end{array}$ & $0.275^{* * *}$ & $0.676^{* * *}$ & $0.553^{* * *}$ \\
$\begin{array}{l}\text { 1. Black Sea } \\
\text { 2. West Africa }\end{array}$ & $0.253^{* * *}$ & $0.627^{* * *}$ & $0.501^{*}$ \\
$\begin{array}{l}\text { 3. All others } \\
\text { 1. Black Sea }\end{array}$ & $0.182^{* * *}$ & $0.560^{* * *}$ & $0.461^{\mathrm{ns}}$ \\
$\begin{array}{l}\text { 2. West Africa } \\
\text { 3. Portugal }\end{array}$ & & & \\
$\begin{array}{l}\text { 4. All others } \\
\text { 1. Black Sea }\end{array}$ & $0.063^{* * *}$ & $0.428^{* * *}$ & $0.390^{\mathrm{ns}}$ \\
$\begin{array}{l}\text { 2. West Africa } \\
\text { 3. Portugal }\end{array}$ & & & \\
4. France & & & \\
5. All others & & & \\
All locations tested & N/A & $0.225^{* * *}$ & N/A \\
individually & & & \\
\hline
\end{tabular}

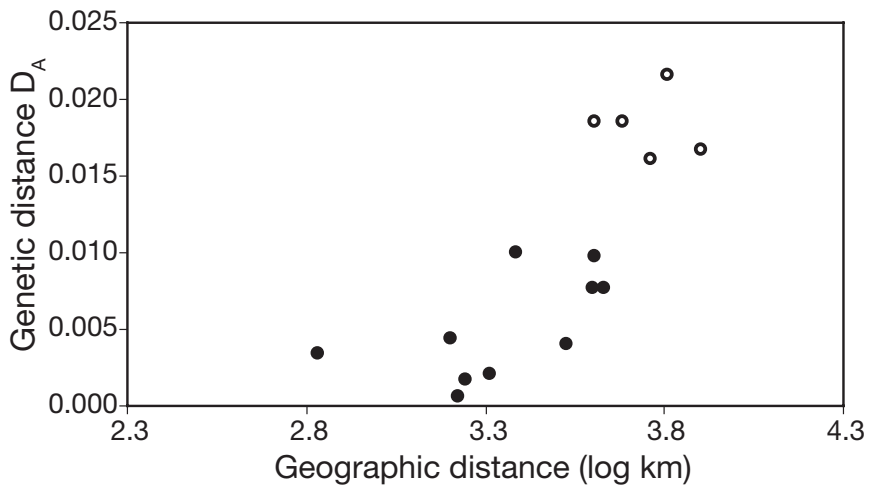

Fig. 2 Phocoena phocoena. Relationship between geographic (logkm) and genetic distance $\left(D_{A}\right)$ for porpoises from the eastern Atlantic (@). O: comparisons involving the Black Sea population

$\left(F_{S}=1.5\right)$, but was significant for the grouped European sampling areas $\left(F_{S}=-23.6, \mathrm{p}<0.001\right)$. When examined for each European population separately, only Norway showed a significant value $\left(F_{S}=-16.4\right.$, $\mathrm{p}<0.001)$. This strongly suggests there has been a recent demographic change for harbour porpoises in the more northern waters, mainly associated with the Norwegian coast. Given this result, a mismatch distribution was then constructed for porpoises from Norway, and demographic parameters estimated for the expansion model (Fig. 3). The observed mismatch distribution was not significantly different from the expected distribution for a demographic expansion (Fig. 3, sum of squared deviations, $\mathrm{SSD}=0.014 ; \mathrm{p}=$ 0.90). Surprisingly, there were 2 peaks in the mismatch distribution, which is unexpected for a population that has recently undergone a demographic change, as the distribution is expected to be smooth for a population that has recently undergone a demographic expansion.

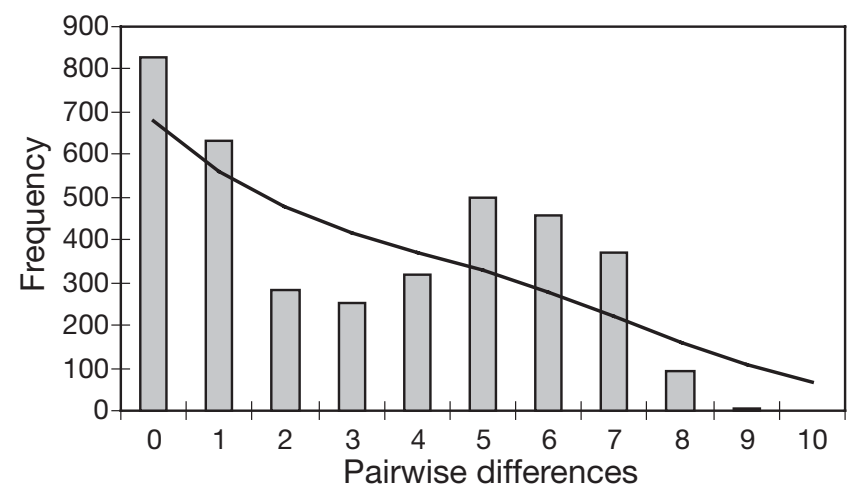

Fig. 3 Phocoena phocoena. Mismatch distribution for haplotypes from the Norwegian sample. Grey bars: observed distribution of pairwise differences among haplotypes; black line: expected distribution of pairwise differences under a model of sudden expansion 
The timing of the putative demographic change for porpoises from Norway was then approximated given the model estimates for $\tau$ (6.528) and the $95 \%$ CI for $\tau$ (2.217 to 14.278). A range for $u(0.0000822$ to 0.0001072$)$ was taken into account in this estimate (see 'Materials and methods' for calculations). The rough estimate for the timing of a demographic change along the coast of Norway would be approximately 30000 to 40000 generations given the estimate of $\tau$. Using the $95 \%$ CI intervals at the higher mutation rate, the estimated time in number of generations would be 10000 to 67000 generations. Using the $95 \%$ CI intervals and the lower mutation rate the estimate would be 13000 to 87000 generations).

The network of haplotypes showed signs of a star phylogeny consistent with recent population expansion mainly associated with the N1 haplotype (Fig. 4). Haplotype N1 has its highest frequency in porpoises from Norway and the North Sea (Table 1, Fig. 4). There was no obvious geographic pattern in the network, although Norwegian haplotypes were rarely in association with either the more common southern haplotypes S6 and S8 (Portugal and France), or the common West African haplotypes (S15 and S16).

\section{DISCUSSION}

Harbour porpoises show substantial geographic structuring in the southeastern North Atlantic consistent with Gaskin's (1984) original population definitions. Although sample sizes were limited, porpoises from the Black Sea and from West Africa differed most markedly from the other populations, and share no haplotypes with any other populations. Rosel et al. (1995) demonstrated that porpoises from the Black Sea shared no haplotypes with porpoises from other areas of the North Atlantic, first suggesting that the Black Sea may be totally isolated from the Atlantic. As porpoises are essentially absent from the Mediterranean, and there are large genetic differences between the Black Sea populations and even the nearest Eastern Atlantic populations (Portugal, West Africa), the present results lend additional weight to the hypothesis that Black Sea porpoises have long been in isolation.

Although West Africa also shared no haplotypes with any other populations, this region may not be completely isolated from the more northern populations. There are only a few records from North Africa (Jefferson et al. 1997), so it is unknown whether there is an

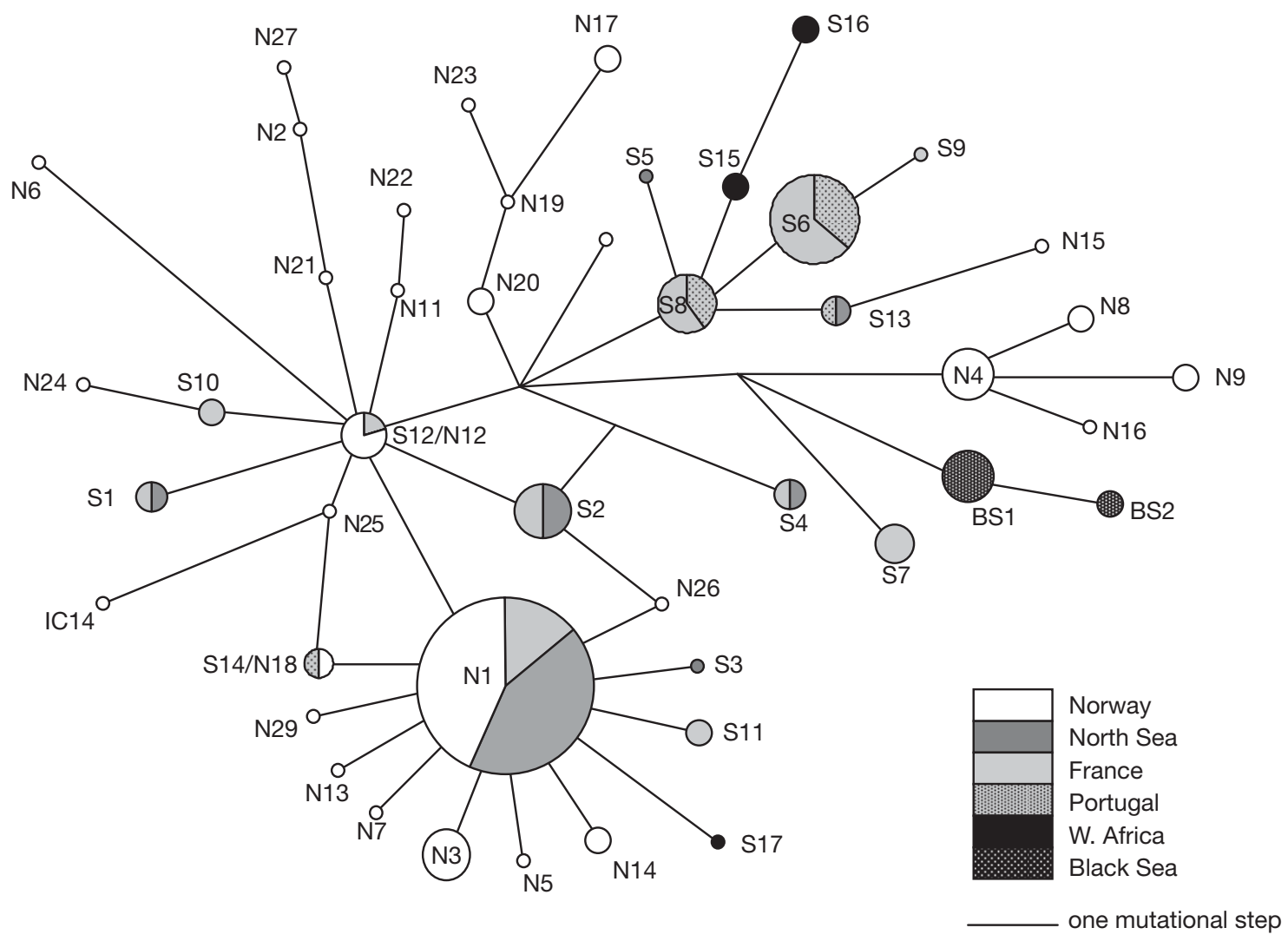

Fig. 4. Phocoena phocoena. Median-joining network of mtDNA haplotypes from the eastern North Atlantic. The size of the circles corresponds to the relative frequencies of haplotypes, and scale bar for one mutational step is shown. Haplotypes are partitioned in shades of grey according to sampling area. Haplotype names as in Table 1 
actual gap in the distribution between Portugal and Africa. However, some studies suggest that porpoises occur continuously from the Gambia/Senegal across the Straits of Gibraltar (see Gaskin 1984, Donovan \& Bjørge 1995, Jefferson et al. 1997). Essentially, there is a lack of distribution information from this area which precludes any concrete conclusions, but the significant genetic differences do suggest that there is limited gene flow between West Africa and Europe. This is consistent with the SAMOVA results, which suggest that on a regional scale, West Africa should be considered a separate population from all the European populations.

The AMOVA shows differences within the European sampling areas (Portugal, France, North Sea, Norway), which implies there is genetic structure along the European coast. However, the localities sampled for this study represent opportunistic sampling within the continuous distribution of this species along the coast of Europe. To fully understand the patterns of genetic structure across this geographic region, more comprehensive sampling would be needed. Nevertheless, our results suggest that porpoises along the coast of Europe are not homogeneous.

\section{Historical biogeography of porpoises in the northeast Atlantic}

North of the English Channel, most studies have indicated that genetic differences are generally low with signs of recent population expansions (Walton 1997, Tolley et al. 1999, Andersen et al. 2001). For example, a previous study suggested there are no genetic differences among sampling localities along the coast of Norway, a region that stretches over $2500 \mathrm{~km}$ (Tolley et al. 1999). Weak genetic structure has been detected for porpoises from the relatively small area encompassing the North Sea, Kattegat Sea, Skagerrak Sea, and the Baltic Sea (Walton 1997, Wang \& Berggren 1997, Andersen et al. 2001). Porpoises from these areas have been shown to differ from those along the west coast of Norway (Wang \& Berggren 1997, Andersen et al. 2001). This pattern of weak genetic structure in the north is in contrast to that found for the more southern areas (present study) where genetic differences are present, rather than absent, in similar sized geographic areas. For example, the present results show that there is substantial genetic structure from the English Channel to Africa. Thus, there is strong genetic structuring in the southern edge of the range (West Africa), moderate genetic structuring toward the middle of the range (within Europe), and no detectable genetic structuring in the north of the range (along the coast of Norway). Fur- thermore, the northern part of the range shows strong signs of recent demographic changes (present study, Tolley et al. 2001), whereas signs of demographic changes in the middle of the range are unclear and/or inconsistent (Tolley et al. 1999, Andersen et al. 2001). In the southern part of the range, there are presently no detectable signs of demographic changes, suggesting that the southern populations have not undergone any recent population expansions and/or contractions in response to climatic shifts.

The pattern of population structure and signs of demographic changes seen here are indicative of a 'leading edge effect' (Hewitt 2000). Leading edges are created when a species colonises a geographic area that was previously unavailable. The leading edge is characterised by lack of genetic structure, high frequency of a single haplotype, and lack of mutationdrift equilibrium (Hewitt 2000), such as that observed for porpoises from Norway. The high occurrence of the N1 haplotype in both Norway and the North Sea (Walton 1997, Tolley et al. 1999), but the low occurrence in the southernmost areas suggest this N1 lineage has dominated the northerly recolonization.

The leading edge effect is most likely the result of an initial population contraction during the last ice age into a southern refuge between Iberia and Senegal, followed by a post-glacial range expansion into northern areas. The north Atlantic environment has changed considerably throughout the Pleistocene, due to persistent and repeated glaciations. During the most recent ice age, the polar front shifted as far south as the Iberian Peninsula in the eastern Atlantic, but the $20^{\circ} \mathrm{C}$ thermocline shifted only marginally southwards (Fig. 1, temperature data from Lowe \& Walker 1984). Assuming their ecological requirements throughout the last ice age were similar to what they are today, porpoises would have been driven south, but also constricted in the zone between the polar front and the $20^{\circ} \mathrm{C}$ thermocline (Fig. 1). Thus, the most likely location of an eastern Atlantic refugium would have been from the Iberian Peninsula (ca. $40^{\circ} \mathrm{N}$ ) southwards along the coast of Africa to Sierra Leone at approximately $7^{\circ} \mathrm{N}$ (ca. $4200 \mathrm{~km}$ of coastline).

It is worth noting that the N1 haplotype, which dominates the leading edge, was not found in the putative refugium (West Africa and the Iberian Peninsula). There are several possible explanations for the absence of the N1 haplotype in the putative refuge: (1) N1 is present in West Africa/Iberia, but sample sizes from these areas were too small to detect its presence; (2) West Africa/Iberia has gone through a bottleneck and has lost the N1 haplotype; (3) N1 was never common in West Africa/Iberia but became common in the northern areas after the founder event; (4) 
West Africa/Iberia were not the focal point of the refugium and the populations in these areas are the result of a separate founder event from an unknown area, where N1 was not common. The marginal location of the West African haplotypes S16 and S17 in the network (Fig. 4) could be used to argue that this population is derived from a separate founding event and has remained isolated for an extended period of time. In contrast, the West African haplotype S17 is closely related to N1, possibly suggesting that N1 is present in West Africa, but was unsampled in this study. If so, it would be reasonable to suggest that the N1 haplotype gained dominance in the northward expansion from a North African refuge. Nevertheless, it remains to be explained why the S15 and S16 haplotypes are in a different part of the network to S17. This disjoint pattern could be the result of either the small sample size in West Africa, or alternatively, lineage extinctions due to genetic drift in a small population in West Africa that have eliminated haplotypes from the network. It is thought that the trailing edge of an expansion will experience lineage extinctions and a reduction in population numbers that could result in severe bottlenecks (Hewitt 2000). Unfortunately, the sample size from West Africa $(n=5)$ makes it difficult to make firm conclusions, but these results seem to suggest that West Africa may be the trailing edge of the expansion.

Regardless of these other possibilities, as the sea ice began a slow retreat, porpoises would have been able to colonize northwards from the refugium as suitable habitat became available (Fig. 1). The timing for a demographic change along the leading edge (Norway) was estimated to be approximately 30000 generations, which equates to $210000 \mathrm{yr}$. This predates the present Holocene interglacial (ca. 10000 to 16000 yr ago, Lowe \& Walker 1984), as well as the Eemian interglacial (which ended ca. 110000 yr ago). The lower limit for a demographic change was estimated to be around 10000 generations, or 70000 yr which corresponds with the onset of the Wisconsin-Weichsel glaciation (which began ca. $70000 \mathrm{yr}$ ago). In addition to the full interglacial period, there were also a number of episodic, short-lived warm interstadial periods in early sub-stages of the glaciation (Adams et al. 1999), and the polar front is thought to have advanced and retreated a number of times during this period (Lowe \& Walker 1984). The mismatch distribution at its lower limit reflects either an expansion corresponding with interstadial events, or perhaps events that precede the Eemian interglacial. Regardless, the signature does not seem to be result of the present Holocene interglacial. The mismatch distribution, while not different from expected for a population that has recently expanded, displays 2 modes. This bimodal distribution could be reflective of episodic expansions and contractions corresponding to fluctuating changes in the position of the polar front. If so, the re-colonisation into the northern regions is more complex than a simple, singular expansion event. Furthermore, initial expansions are known to obscure the signatures of more recent expansions (Rogers 1995). In all, it appears that the expansion model is insufficient to describe these demographic changes, although the pattern possibly suggests that population expansions have been episodic, and began sometime in the late Quaternary.

The presence of a leading edge has been detected for a variety of taxa, especially in the terrestrial environment of the Northern hemisphere and a number of refuges have been identified (see Hewitt 2000). Although less attention has been paid to the marine environment, the pattern of recolonization and the presence of leading edges are known to be congruent across some taxa. Such congruent patterns for coldadapted marine mammals suggest that some species have been able to colonise the northernmost regions of the Atlantic, which have only recently re-opened. For example, fin whales Balaenoptera physalus show strong signs of population expansions in the most northern regions of the western North Atlantic, but such signatures are absent in the more southern areas, such as Spain and the Mediterranean (Bérubé et al. 1998). Beluga whales Delphinapterus leucas (O'CorryCrowe et al. 1997, Brown Gladden et al. 1999) and narwhals Monodon monoceros (Palsbøll et al. 1997) also show signs of recent population expansions, presumably corresponding with the early Holocene and the opening of the Arctic marine regions.

\section{Historical biogeography of porpoises in the Black Sea}

The Black Sea was periodically isolated from the Mediterranean during much of the Quaternary due to a lowering of sea levels causing the closure of the Straits of Bosporus. It was most recently re-connected with the Mediterranean ca. $7000 \mathrm{yr}$ ago in an abrupt drowning event (Ryan et al. 1997), whereas the Atlantic has maintained its connection with the Mediterranean since the early Pliocene (Butler \& Lickorish 1997). Aside from a small number of individuals in the Aegean Sea near the Straits of Bosporus (Frantzis et al. 2001), porpoises are not found in the Mediterranean, despite these open connections with both the Black Sea and the Atlantic.

Black Sea porpoises are genetically divergent from Atlantic porpoises (ca. $\mathrm{D}_{\mathrm{A}}=0.020$, Fig. 2; uncorrected p-distances $=0.015$ to 0.020 ), suggesting that porpoises have been isolated in the Black Sea for an extended 
period of time. If the range of sequence divergences $(d=0.015$ to 0.020$)$ and the rough mutation rate of ca. 3.3 to $4.3 \% \mathrm{Myr}^{-1}$ are used to estimate time since divergence $(T=(d / 2) / \mu)$, Black Sea porpoises could have been isolated from the Atlantic beginning around ca. 175000 to $300000 \mathrm{yr}$ ago. In addition to the Black Sea being open at present, there have been 2 recent major saline epochs, suggesting that it has been periodically open to the Mediterranean. The most recent (Saline Epoch II) was ca. 120000 yr ago, generally corresponding to the Eemian interglacial and the rise of sea levels (Schrader 1979). Saline Epoch III was between ca. 180000 to 210000 yr before present, corresponding with the Holsteinian interglacial (Schrader 1979). The Black Sea was first isolated starting at the Plio-Pleistocene boundary (ca. 1.8 Myr before present) and the isolation lasted until Saline Epoch III. Thus, porpoises could have first colonised the Black Sea during its opening ca. 210000 yr ago (Salinity Epoch III). Marine faunal records suggest that the Mediterranean was cool during this time (Emig \& Geistdoerfer 2004), possibly setting the conditions that would have allowed porpoises through the Mediterranean to the Black Sea. The subsequent closing of the Black Sea would have isolated porpoises around $180000 \mathrm{yr}$ ago, and this geological date is consistent with the rough molecular dates for the divergence of the Black Sea population. An alternative scenario is that the Black Sea porpoises became established as the result of a more recent founder event by a few individuals. Should this have been the case, the apparent genetic divergence would be artificially inflated, causing an overestimate of this coalescent time.

In the case of the long-term isolation scenario, the question remains as to why porpoises did not re-enter the Black Sea from the Atlantic/Mediterranean (or conversely, leave the Black Sea) during the Eemian interglacial, or during the present interglacial. It might be hypothesised that thermal requirements during the recent interglacials have not been met. The present Mediterranean summertime sea surface temperatures exceed the 20 to $24^{\circ} \mathrm{C}$ thermocline that generally defines porpoise distribution. The Black Sea however, is cooler and does not exceed these temperatures (based on satellite data from www.osdpd.noaa.gov) perhaps providing a more suitable thermal regime in which to live. During the Eemian interglacial, as today, the Mediterranean had a temperate fauna (Emig \& Geistdoerfer 2004) with water temperatures exceeding 20 to $24^{\circ} \mathrm{C}$, so it is possible that porpoises also avoided the region during this period. This would explain the historical as well as the continued separation of the Black Sea from the Atlantic population, despite the open sea connection. The lack of gene flow between the Atlantic, Mediterranean, and the Black Sea has been demonstrated for other cold-water marine organisms (Quesada et al. 1995, Ladoukakis et al. 2002, Papadopoulous et al. 2005), and it appears that divergence among the fauna in these basins also dates back to the middle Pleistocene rather than to the recent drowning of the Black Sea shelf (Papadopoulous et al. 2005). This is not inconsistent with the results found in the present study, where the mitochondrial coalescent estimates predate the Eemian.

\section{CONCLUSIONS}

The present results lend support to the hypothesis that global climatic changes have had substantial impacts on the genetic population structure of marine taxa in the North Atlantic, and that there are parallel patterns of recolonization. For harbour porpoises, the northernmost areas show leading edge effects in the eastern North Atlantic, similar to patterns observed for this species in the western North Atlantic (Rosel et al. 1999, Tolley et al. 2001). Furthermore, climate seems to have played a role in the long-term isolation between the Atlantic and the Black Sea, leading to divergence among populations. Despite the large range for the dates and the uncertainty in estimating mutation rates, these data help to identify the approximate time periods of major demographic events.

The present results suggest that major climatic shifts can affect genetic structure on an oceanic scale. Obviously, such processes and patterns must be carefully considered for species at risk of population declines, such as the harbour porpoise. Population genetic structure analyses are increasingly being used as aids in formulating management plans. However, in some instances where species have undergone recent demographic changes, leading edge effects may have a strong influence on the observable genetic structure, despite low gene flow. The result can be lack of detectable population genetic structure over large regions, such as along the coast of Norway. In such circumstances, genetic tools may not be the most sensitive for providing information on population dynamics, and it would be extremely prudent to integrate information from ecological markers to fully understand the contemporary structure of populations.

Acknowledgements. Samples for this study were kindly provided by M. Addink and C. Smeenk of the Naturalis Museum, Leiden, the Netherlands; M. Sequeira, Instituto da Conservacao da Natureza, Lisbon, Portugal; W. Dabin and V. Ridoux, Centre de Recherche sur les Mammifères Marins (CRMM), La Rochelle, France. We also thank L. Adams, R. Pugh, S. Kingston, and A. Sellas for support in the lab, and M. Hofreiter for the bone/teeth extraction protocol. Assistance was also given by N. Øien (Institute of Marine Research, Bergen, 
Norway), and financial support was provided by the Norwegian Research Council, and the U.S. National Marine Fisheries Service. Laboratory work was carried out at the National Marine Fisheries Service, Southeast Fisheries Science Center.

\section{LITERATURE CITED}

Adams J, Maslin M, Thomas E (1999) Sudden climate transitions during the Quaternary. Prog Phys Geogr 23:1-36

Andersen LW, Ruzzante DE, Walton M, Berggren P, Bjørge A, Lockyer C (2001) Conservation genetics of harbour porpoises, Phocoena phocoena, in eastern and central North Atlantic. Conserv Genet 2:309-324

Bérubé M, Aguilar A, Dendanto D, Larsen F and 5 others (1998) Population genetic structure of North Atlantic, Mediterranean Sea and Sea of Cortez fin whales, Balaenoptera physalus (Linnaeus 1758): analysis of mitochondrial and nuclear loci. Mol Ecol 7:585-599

Brown Gladden JG, Ferguson MM, Friesen MK, Clayton JW (1999) Population structure of North American beluga whales (Delphinapterus leucas) based on nuclear DNA microsatellite variation and contrasted with the population structure revealed by mitochondrial DNA variation. Mol Ecol 8:347-363

Butler RWH, Lickorish WH (1997) Using high resolution stratigraphy to date fold and thrust activity: examples from the Neogene of south-central Sicily. J Geol Soc 154:633-643

Donovan GP, Bjørge A (1995) Harbour porpoises in the North Atlantic (extract from the Report of the IWC Scientific Committee). Rep Int Whal Comm Spec Issue 16:3-25

Dupanloup I, Schneider S, Excoffier L (2002) A simulated annealing approach to define the genetic structure of populations. Mol Ecol 11:2571-81

Emig CC, Geistdoerfer P (2004) The Mediterranean deep-sea fauna: historical evolution, bathymetric variations and geographical changes. Notebooks Geol 1:1-10

Excoffier L, Schneider S (1999) Why hunter-gatherer populations do not show signs of Pleistocene demographic expansions. Proc Natl Acad Sci USA 96:10597-10602

Frantzis A, Gordon J, Hassidis G, Komenou A (2001) The enigma of harbor porpoise presence in the Mediterranean Sea. Mar Mamm Sci 17:937-943

Fu YX (1997) Statistical tests of neutrality of mutations against population growth, hitchhiking and background selection. Genetics 147:915-925

Gaskin DE (1984) The harbour porpoise, Phocoena phocoena (L.): regional populations, status and information on direct and indirect catches. Rep Int Whal Comm 34:569-586

Harris SA (2005) Thermal history of the Arctic Ocean environs adjacent to North America during the last 3.5 Ma and a possible mechanism for the cause of cold events (major glaciations and permafrost events). Prog Phys Geogr 29: 218-237

Hewitt G (2000) The genetic legacy of Quaternary ice ages. Nature 405:907-913

Jefferson TA, Curry BE, Leatherwood S, Powell JA (1997) Dolphins and porpoises of West Africa: a review of records (Cetacea: Delphinidae, Phocoenidae). Mammalia 61: 87-108

Ladoukakis ED, Saavedra C, Magoulas A, Zouros E (2002) Mitochondrial DNA variation in a species with two mitochondrial genomes: the case of Mytilus galloprovincialis from the Atlantic, the Mediterranean and the Black Sea. Mol Ecol 11:755-769

Lowe JJ, Walker MJC (1984) Reconstructing Quaternary environments. Longman Group, Hong Kong
O'Corry-Crowe GM, Suydam RS, Rosenberg A, Frost KJ, Dizon AE (1997) Phylogeography, population structure and dispersal patterns of the beluga whale Delphinapterus leucas in the western Nearctic revealed by mitochondrial DNA. Mol Ecol 6:955-970

Palsbøll PJ, Heide-Jørgensen MP, Dietz R (1997) Population structure and seasonal movements of narwhals, Monodon monoceros, determined from mtDNA analysis. Heredity 78: 284-292

Papadopoulous LN, Peijnenburg KTCA, Luttikhuizen PC (2005) Phylogeography of the calanoid copepods Calanus helgolandicus and C. euxinus suggests Pleistocene divergences between Atlantic, Mediterranean, and Black Sea populations. Mar Biol 147:1353-1365

Posada D, Crandall KA (1998) Modeltest: testing the model of DNA substitution. Bioinformatics 14:817-818

Quesada H, Beynon CM, Skibinski DOF (1995) A mitochondrial DNA discontinuity in the mussel Mytilus galloprovincialis Lmk: Pleistocene vicariance biogeography and secondary intergradation. Mol Biol Evol 12: $521-524$

Read AJ, Westgate AJ (1997) Monitoring the movements of harbour porpoises (Phocoena phocoena) with satellite telemetry. Mar Biol 130:315-322

Rogers AR (1995) Genetic evidence for a Pleistocene population explosion. Evolution 49:608-615

Rosel PE, Dizon AE, Haygood MG (1995) Variability of the mitochondrial control region in populations of the harbour porpoise, Phocoena phocoena, on interoceanic and regional scales. Can J Fish Aquat Sci 52:1210-1219

Rosel PE, France SF, Wang JY, Kocher TD (1999) Genetic structure of harbour porpoise Phocoena phocoena populations in the Northwest Atlantic based on mitochondrial and nuclear markers. Mol Ecol 8:S41-S54

Rosel PE, Frantzis A, Lockyer C, Komnenou A (2003) Source of Agean Sea harbour porpoises. Mar Ecol Prog Ser 247: $257-261$

Ryan WBF, Pitman WC, Major CO, Shimkus K and 6 others (1997) An abrupt drowning of the Black Sea shelf. Mar Geol 138:119-126.

Schneider S, Roessli D, Excoffier L (2000) Arlequin ver. 2.000: a software for population genetics data analysis. Genetics and Biometry Laboratory, University of Geneva

Schrader HJ (1979) Quaternary paleoclimatology of the Black Sea basin. Sediment Geol 23:165-180

Swofford, DL (2002) PAUP*: Phylogeny analysis using parsimony ( ${ }^{*}$ and other methods), version 4.0b10. Sinauer Associates, Sunderland, MA

Thompson JD, Gibson TJ, Plewniak F, Jeanmougin F, Higgins DG (1997) The ClustalX windows interface: flexible strategies for multiple sequence alignment aided by quality analysis tools. Nucleic Acids Res 24:4876-4882

Tolley KA, Heldal HE (2002) Inferring ecological separation from regional differences of radioactive caesium in harbour porpoises Phocoena phocoena. Mar Ecol Prog Ser 228:301-309

Tolley KA, Rosel PE, Walton M, Bjørge A, Øien N (1999) Genetic population structure of harbour porpoises (Phocoena phocoena) in the North Sea and Norwegian waters. J Cetacean Res Manage 1:256-274

Tolley KA, Vikingsson G, Rosel PE (2001) Mitochondrial DNA sequence variation and phylogeographic patterns in harbour porpoises (Phocoena phocoena) from the North Atlantic. Conserv Genet 2:349-361

Walton MJ (1997) Population structure of harbour porpoises Phocoena phocoena in the seas around the UK and adjacent waters. Proc R Soc Lond B Biol Sci 264:89-94 
Wang JY, Berggren P (1997) Mitochondrial DNA analysis of harbour porpoises (Phocoena phocoena) in the Baltic Sea, the Kattegat-Skagerrak Seas and off the west coast of Norway. Mar Biol 127:531-537

Wang JY, Gaskin DE, White BN (1996) Mitochondrial DNA analysis of harbour porpoise, Phocoena phocoena,

Editorial responsibility: Otto Kinne (Editor-in-Chief), Oldendorf/Luhe, Germany subpopulations in North American waters. Can J Fish Aquat Sci 53:1632-1645

Westgate AJ, Tolley KA (1999) Geographical differences in organochlorine contaminants in harbour porpoises Phocoena phocoena from the western North Atlantic. Mar Ecol Prog Ser 177:255-268

Submitted: December 6, 2005; Accepted: March 30, 2006 Proofs received from author(s): October 18, 2006 